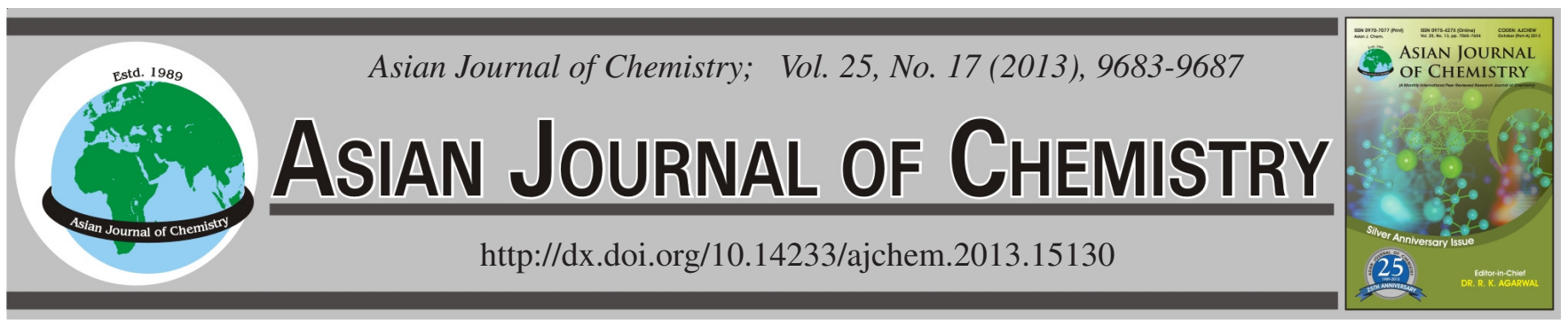

\title{
Antioxidant Activity of Rumex conglomeratus P. Collected from Turkey
}

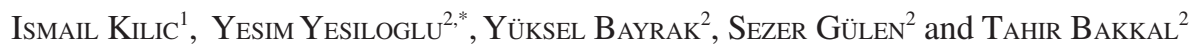

${ }^{1}$ Faculty of Education, Trakya University, Edirne, Turkey

${ }^{2}$ Department of Chemistry, Faculty of Science, Trakya University, Edirne, Turkey

*Corresponding author: Fax: +90 284 2351198; Tel: +90 284 2359592; E-mail: yesimyesiloglu@ trakya.edu.tr

(Received: 11 January 2013;

Accepted: 14 October 2013)

AJC-14254

\begin{abstract}
Plants contain a wide variety of free radical scavenging molecules, such as flavonoids, anthocyanins, carotenoids, dietary glutathionine, vitamins and endogenous metabolites and such natural products are rich in antioxidant activities. Rumex conglomeratus $\mathrm{P}$. is widely spread in Turkey and used as an anticonstipate in traditional medicine. In this study, the antioxidant activity of water extract of $R$. conglomeratus was evaluated using different antioxidant tests. In addition, carotenoid content and proline level of $R$. conglomeratus were also determined. The results were compared with natural and synthetic antioxidants. The results showed that $R$. conglomeratus contained naturally occuring antioxidant components and possessed antioxidant activity which may be attributed to its radical scavenging and metal chelating activities. It was concluded that $R$. conglomeratus might be a potential source of antioxidants.
\end{abstract}

Key Words: Antioxidant activity, Flavonoids, Polyphenol content, $R$. conglomeratus.

\section{INTRODUCTION}

Free radicals have been claimed to play an important role in affecting human health by causing several diseases including cancer, hypertension, heart attack and diabetes. Dietary intake of phenolic compounds correlates with reduced coronary heartrelated properties, such as antioxidant, anticancer, antiviral and anti-inflammatory activities ${ }^{1}$.

Polyphenols are common constituents of the human diet, with fruits and vegetables being the major dietary source of these bioactive compounds. The possible health benefits of polyphenol consumption have been suggested to derive from their antioxidant properties. Evidence for their role in the prevention of degenerative diseases is emerging. There are huge varieties of antioxidants contained in fruits. Several methods have been developed to estimate the antioxidant capacity of different plant materials ${ }^{2,3}$. Phenolic compounds are ubiquitous in plants and when plant foods are consumed, these phytochemicals contribute to the intake of natural antioxidants in the human diets and has to be resolved to obtain the optimum antioxidant efficiency.

Proline is one of the 20 amino acids found in proteins. Pentose phophate pathway is regulated by synthesis of cytosolic proline which oxidizes $\mathrm{NADPH}_{2}$. The role of prolinelinked pentose phosphate pathway in plants is studied and it is concluded that plants with high proline content exhibit high concentration of phenolic compounds ${ }^{4}$. Therefore, proline content of edible plants may be accepted as a measure of its antioxidant capacity.

Rumex species are widely distributed in Turkey. The root and leaves are traditionally used for the treatment of purgative, constipate, depurative and tonic in Turkish folk medicine ${ }^{5}$. The leaves can be cooked like spinach. The leaves of plant contain nutritionally significant concentrations of vitamin $\mathrm{C}$. The genus Rumex, belonging to the polygonaceae is characterized by a high percentage of anthraquinones, naphthalenes, flavonoids and other phenolic compounds ${ }^{6}$. No reports are available on the antioxidant activity of Rumex species. $R$. conglomeratus, locally known as "labada", is one of the most popular leafy vegetables consumed in Thrace region of Turkey. The present study was undertaken to examine antioxidant activities of water extract of $R$. conglomeratus through various in vitro models. Additionally, determination of proline levels of the extract as indicative of antioxidant capacity was aimed.

\section{EXPERIMENTAL}

$\alpha$-Tocopherol, potassium persulfate, 2,2-azino-bis-(3ethylbenzothiazoline-6-sulphonic acid) (ABTS), butylated hydroxyanisole (BHA), phenazine methosulfate (PMS), 1,1diphenyl-2-picrylhydrazyl (DPPH), gallic acid and 3-(2-pyridyl)5,6-bis(4-phenyl-sulfonic acid)-1,2,4-triazine (ferrozine), Folin-Ciocalteau were obtained from Sigma (Sigma-Aldrich $\mathrm{GmbH}$, Sternheim, Germany). Ammonium molybdate, sodium phosphate and sulphuric acid were purchased from Merck. 
All other chemicals used were in analytical grade and obtained from either Sigma-Aldrich or Merck.

Fresh leaves of $R$. conglomeratus were collected from Tekirdag City (Tekirdag, Turkey). Plant materials were washed with distilled water and dried at room temperature. The dried plant was stored in $-20{ }^{\circ} \mathrm{C}$ until used.

Preparation of extracts: Dried $R$. conglomeratus leaves $(25 \mathrm{~g})$ were extracted by adding $500 \mathrm{~mL}$ distilled water and boiled for $0.5 \mathrm{~h}$. The extract was then filtered and evaporated to dryness under reduced pressure and controlled temperature $\left(40-50{ }^{\circ} \mathrm{C}\right)$ in a rotary evaporator. The water extract yielded a dark brown solid residue weighing $13.35 \mathrm{~g}(53.40 \%)$ and was kept at $-20^{\circ} \mathrm{C}$. The extract was dissolved in distilled water and used for the assessment of antioxidant, carotenoid and proline content.

Determination of total carotenoid content: Total carotenoid content was determined by the method of Alasalvar et al. ${ }^{7}$ with slight modification. In brief, $400 \mathrm{mg}$ of $R$. conglomeratus was extracted with $5 \mathrm{~mL}$ of acetone-water $(9: 1$, $\mathrm{v} / \mathrm{v}$ ) and centrifuges at $3000 \mathrm{rpm}$ for $10 \mathrm{~min}$ at $4{ }^{\circ} \mathrm{C}$. The clear supernatant was withdrawn and extraction was repeated for another five to six times with $3 \mathrm{~mL}$ of acetone-water until no colour was extracted. Extracts obtained were pooled and measured against an acetone blank at $471 \mathrm{~nm}$ using a UV-1601 spectrophotometer (Shimadzu, Kyoto, Japan). Total carotenoid content was calculated according to the following equation:

Total carotenoid content $(\%)=\frac{\mathrm{Abs}_{\max } \times 25 \mathrm{~mL} \text { acetone } \times 100}{\text { Sample weight }}$

Determination of total phenolic compounds: Total phenolics in $R$. conglomeratus extract were determined with Folin-Ciocalteau reagent, according to the method of Slinkard and Singleton ${ }^{8}$. Briefly, $1 \mathrm{~mL}$ of the $R$. conglomeratus extracts $(25-125 \mu \mathrm{g} / \mathrm{mL})$ was transferred into test tubes and their volumes made up to $46 \mathrm{~mL}$ with distilled water. After addition of $1 \mathrm{~mL}$ Folin-Ciocalteau reagent and $3 \mathrm{~mL} 2 \% \mathrm{Na}_{2} \mathrm{CO}_{3}$ solution, tubes were vortexed and then allowed to stand for $2 \mathrm{~h}$ intermittent shaking. The absorbance was measured at $760 \mathrm{~nm}$ in a spectrophotometer. The total phenolic compounds in the $R$. conglomeratus extracts were calculated as $\mathrm{mg}$ of gallic acid equivalent from the calibration curve and as $\mathrm{mg}$ gallic acid equivalents per $g$ of extracts. The data were presented as the average of triplicate analyzes.

Determination of total flavonoid content: Total flavonoid content was determined by using a method described by Wang et al. ${ }^{9}$ with minor modification using (+)-catechin as standard flavonoid compound. Briefly, $10 \mathrm{~mL}$ of each extract $(1000$ $\mu \mathrm{g} / \mathrm{mL})$ or $(+)$-catechin standard solution $(25-125 \mu \mathrm{g} / \mathrm{mL})$ was mixed with $1 \mathrm{~mL}$ of a $5 \%$ sodium nitrite solution. After 6 min, $1 \mathrm{~mL}$ of a $10 \%$ aluminium nitrate solution was added and the mixture was allowed to stand for a further 6 min before $10 \mathrm{~mL}$ of a $4.3 \% \mathrm{NaOH}$ was added. The mixture was brought to $25 \mathrm{~mL}$ with distilled water and mixed well. After $15 \mathrm{~min}$, the absorbance was measured at $510 \mathrm{~nm}$ using a spectrophotometer.

Proline content: Proline analysis was performed according to Bates ${ }^{10}$. Briefly, $50 \mathrm{mg}$ extract was homogenized in
$10 \mathrm{~mL}$ sulphosalicylic acid (3\%) and filtrated through filter paper. Two milliliters of the filtrate were mixed with $2 \mathrm{~mL}$ of acid ninhydrin solution $(1.25 \mathrm{~g}$ ninhydrin $+30 \mathrm{~mL}$ glacial acetic acid $\left.+20 \mathrm{~mL} 6 \mathrm{M} \mathrm{H}_{3} \mathrm{PO}_{4}\right)$ and $2 \mathrm{~mL}$ of glacial acetic acid and kept at $100^{\circ} \mathrm{C}$ for $1 \mathrm{~h}$. Then the reaction was stopped by transferring the mixture to an ice bath. Four milliliters of toluene were added to the mixture and vortexed for 15-20 s. The toluene phase was aspirated and absorbance at $520 \mathrm{~nm}$ was measured using pure toluene reference. A calibration curve was prepared with pure proline. Results were expressed as $\mu \mathrm{g}$ proline/gram extract.

Phosphomolybdate assay: The antioxidant activity of $R$. conglomeratus extract was evaluated by the phosphomolybdenum method according to the procedure of Umamaheswari and Chatterjee ${ }^{11}$. An aliquot of $0.1 \mathrm{~mL}$ of extract was mixed with $1 \mathrm{~mL}$ reagent solution $(0.6 \mathrm{M}$ sulphuric acid, $28 \mathrm{mM}$ sodium phosphate and $4 \mathrm{mM}$ ammonium molybdate). The test tubes were capped with silver foil and incubated in a water bath at $95{ }^{\circ} \mathrm{C}$ for $90 \mathrm{~min}$. After the samples had cooled to room temperature, the absorbance of the mixture was measured at $695 \mathrm{~nm}$ against a blank. Ascorbic acid was used as standard. The antioxidant capacity was estimated using the following formula:

$$
\text { Antioxidant effect }(\%)=\left(\frac{\mathrm{A}_{0}-\mathrm{A}_{1}}{\mathrm{~A}_{0}}\right) \times 100
$$

$\mathrm{A}_{0}$ is the absorbance of the control, $\mathrm{A}_{1}$ is the absorbance of the sample.

Iron(II) chelation activity: The chelating of ferrous ions by the extracts from leaves of $R$. conglomeratus and standard antioxidants was estimated by the method of Dastmalchi et al. ${ }^{12}$. Briefly, extracts $(25-125 \mu \mathrm{g} / \mathrm{mL})$ were added to 0.05 $\mathrm{mL}$ of $2 \mathrm{mM} \mathrm{FeCl}_{2}$ solution. The reaction was initiated by the addition of $0.2 \mathrm{~mL}$ of $5 \mathrm{mM}$ ferrozine solution and the mixture was shaken vigorously and left standing at room temperature for $10 \mathrm{~min}$. Absorbance of the solution was then measured spectrophotometrically at $562 \mathrm{~nm}$. All test and analyses were run in triplicate and averaged. The percentage of inhibition of ferrozine- $\mathrm{Fe}^{2+}$ complex formation was calculated using the formula as follows:

$$
\text { Metal chelating activity }(\%)=\left(\frac{\mathrm{A}_{0}-\mathrm{A}_{1}}{\mathrm{~A}_{0}}\right) \times 100
$$

$\mathrm{A}_{0}$ is the absorbance of the control, $\mathrm{A}_{1}$ is the absorbance of the sample.

Reducing power: The reducing power of the $R$. conglomeratus extract was determined according to the method described by Oyaizu ${ }^{13}$. Different amounts of extracts (25-125 $\mu \mathrm{g} / \mathrm{mL})$ in $1 \mathrm{~mL}$ of distilled water were mixed with $2.5 \mathrm{~mL}$ of phosphate buffer $(0.2 \mathrm{M}$, pH 6.6) and $2.5 \mathrm{~mL}$ potassium ferricyanide $(1 \%)$ and then the mixture was incubated at $50^{\circ} \mathrm{C}$ for $0.5 \mathrm{~h}$. Afterwards, $2.5 \mathrm{~mL}$ of TCA $(10 \%)$ was added to the mixture to stop the reaction, then the mixture was centrifuged at $3000 \mathrm{rpm}$ for $10 \mathrm{~min}$. The supernatant $(2.5 \mathrm{~mL})$ was mixed with $2.5 \mathrm{~mL}$ distilled water and $0.5 \mathrm{~mL} \mathrm{FeCl}_{3}(0.1 \%)$ and then absorbance was measured at $700 \mathrm{~nm}$ in a spectrophotometer. The reducing power of the tested samples increased with the absorbance values. 
DPPH radical scavenging activity: The DPPH $(1,1-$ diphenyl-2-picrylhydrazil) radical scavenging activity of the $R$. conglomeratus extract was measured according to the procedure described by Shimada et al. ${ }^{14}$. Briefly, $0.1 \mathrm{mM}$ solution of DPPH in ethanol was prepared and $1 \mathrm{~mL}$ of this solution was added to $3 \mathrm{~mL}$ of $R$. conglomeratus extracts at different concentrations $(25-125 \mu \mathrm{g} / \mathrm{mL})$. The mixture was shaken vigorously and allowed to stand in the dark at room temperature for $0.5 \mathrm{~h}$. The decrease in absorbance of the resulting solution was then measured spectrophotometrically at $517 \mathrm{~nm}$ against ethanol. All measurements were made in triplicate and averaged. The DPPH radical scavenging activity was calculated using the following equation:

DPPH radical scavenging activity $(\%)=\left(\frac{\mathrm{A}_{0}-\mathrm{A}_{1}}{\mathrm{~A}_{0}}\right) \times 100$

$\mathrm{A}_{0}$ is the absorbance of the control, $\mathrm{A}_{1}$ is the absorbance of the sample.

ABTS $^{\bullet+}$ scavenging activity: The $\mathrm{ABTS}^{\bullet+}$ scavenging activity of the $R$. conglomeratus extracts was measured according to procedure described by Re et al..$^{15}$. $\mathrm{ABTS}^{\bullet+}$ was produced by the reaction between $7 \mathrm{mM} \mathrm{ABTS}^{\bullet}$ in $\mathrm{H}_{2} \mathrm{O}$ and $2.45 \mathrm{mM}$ potassium persulfate, stored in the dark at room temperature for $12 \mathrm{~h}$. Before usage, the $\mathrm{ABTS}^{\bullet+}$ solution was diluted to get an absorbance of $0.700 \pm 0.025$ at $734 \mathrm{~nm}$ with phosphate buffer $(0.1 \mathrm{M}, \mathrm{pH} 7.4)$. Then, $1 \mathrm{~mL}$ of $\mathrm{ABTS}^{\bullet+}$ solution was added to $3 \mathrm{~mL}$ of water extract at different concentrations $(25-125 \mu \mathrm{g} / \mathrm{mL})$. After $0.5 \mathrm{~h}$, the absorbance was taken at $734 \mathrm{~nm}$ using the spectrophotometer. The $\mathrm{ABTS}^{\bullet+}$ scavenging activity was calculated using the following equation:

ABTS radical scavenging activity $(\%)=\left(\frac{\mathrm{A}_{0}-\mathrm{A}_{1}}{\mathrm{~A}_{0}}\right) \times 100$

$A_{0}$ is the absorbance of the control, $A_{1}$ is the absorbance of the sample.

\section{RESULTS AND DISCUSSION}

Total carotenoid, total phenolic, total flavonoid and proline content: The concentrations and compositions of carotenoids are responsible for the diverse and attractive colours observed in foods ${ }^{16}$. Table- 1 summarized the total carotenoid content of $R$. conglomeratus extract ( $24 \%)$. The applicability of objective colour assessments to estimate the carotenoid content of diverse foods has been the goal of several studies conducted in previous years ${ }^{17-19}$.

Plants containing high phenolic compounds can be a good source of antioxidants. For this reason, this information has led to the determination of the total phenolic content of the sample under study. It was determined that there was $43 \mu \mathrm{g}$ gallic acid equivalent of phenolic compounds in the $1 \mathrm{mg}$ of the water extract of $R$. conglomeratus (Table-1).

Flavonoids are natural phenolic compounds and well known antioxidants. Therefore dietary intake of flavonoid- containing foods was suggested to be of benefit for the preservation from free radical damage. The concentration of flavonoids in the $R$. conglomeratus extract was expressed as $\mu \mathrm{g}$ of (+)-catechin equivalent per mg of the extract, as shown in Table-1. It was determined that there was $119 \mu \mathrm{g}(+)-$ catechin equivalent of phenolic compounds in $1 \mathrm{mg}$ of the $R$. conglomeratus extract (Table-1).

Wu et al. ${ }^{20}$ have demonstrated that some amino acids also have antioxidant properties. Proline is one of these antioxidant amino acids. Proline is intracellular nonenzymatic ROS scavenging molecule ${ }^{21}$. Proline provides protecting against stress by maintaining redox homeostasis ${ }^{22}$ and scavenging free radicals and $\operatorname{ROS}^{23}$. In this study, the proline contents increased with increasing concentration and high proline contents (366.57 $\mu \mathrm{g} / \mathrm{g}$ extract) were observed in $50 \mathrm{mg}$ water extract (Table-1).

Phosphomolybdate assay: The phosphomolybdate method has been routinely used to evaluate the antioxidant capacity of extracts. In the presence of extracts, Mo(VI) is reduced to $\mathrm{Mo}(\mathrm{V})$ and forms a green coloured phosphomolybdenum(V) complex, which shows a maximum absorbance at $700 \mathrm{~nm}$. A high absorbance value indicates that the sample possesses high antioxidant activity ${ }^{24}$. All the fractions of $R$. conglomeratus extract showed a significant total antioxidant activity, which was concentration-dependent (Fig. 1). The total antioxidant activity of $R$. conglomeratus extract at $125 \mu \mathrm{g} / \mathrm{mL}$ was 0.714 , significantly lower than ascorbic acid (1.7). The total antioxidant capacity of plant extract may be attributed to their chemical composition and phenolic acid content.

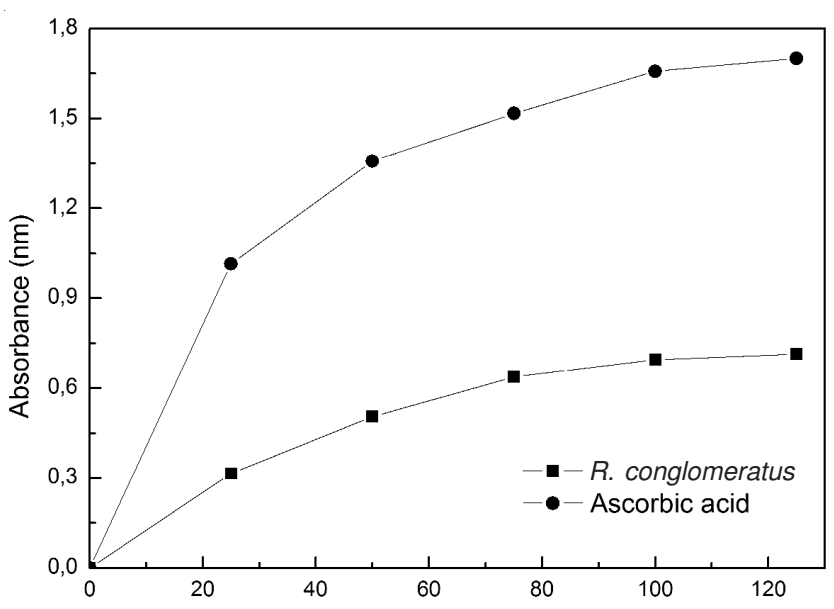

Fig. 1. Antioxidant activity of $R$. conglomeratus extracts. Ascorbic acid was used as reference antioxidant

Iron(II) chelation activity: By forming a stable iron(II) chelate, an extract with high chelating power reduces the free ferrous ion concentration and thus decreases the extent of the Fenton reaction which is implicated in many diseases ${ }^{25}$. Fig. 2 shows, the extent of the reduction, in terms of absorbance

TABLE-1

EXTRACTION YIELD, TOTAL CAROTENOID (CC), PHENOLIC (PC) (AS GALLIC ACID EQUIVALENTS), FLAVONOID (FC) (AS CATECHIN EQUIVALENTS) AND PROLINE CONTENT OF $R$. conglomeratus EXTRACT

\begin{tabular}{cccccc} 
Extract & Extraction yield $(\%)$ & $\mathrm{CC}(\%)$ & $\mathrm{PC}(\mu \mathrm{g} / \mathrm{mg})$ & $\mathrm{FC}(\mu \mathrm{g} / \mathrm{mg})$ & Proline content $(\mu \mathrm{g} / \mathrm{g})$ \\
\hline Water & 53.4 & 24 & 43 & 119 & 366.57 \\
\hline
\end{tabular}




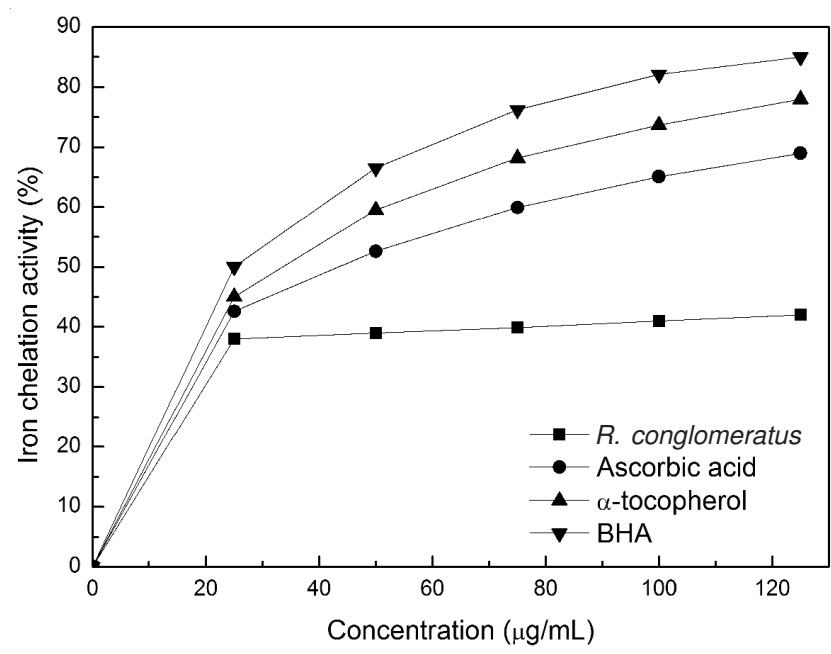

Fig. 2. Iron chelation activity of the extracts from $R$. conglomeratus. $\alpha$ Tocopherol, ascorbic acid and BHA were used as reference antioxidants

values at $700 \mathrm{~nm}$. The chelation activity of water extract (42\%) was not concentration dependent and was found to be below those of tocopherol (78 \%), ascorbic acid (69 \%) and BHA (85\%) at $125 \mu \mathrm{g} / \mathrm{mL}$. The extract showed lower chelation activity than the standards. Chelation activity of extract and standards decreased in order of BHA $>$ tocopherol $>$ ascorbic acid $>$ water extract. It was evident that the extract could inhibit free radical production by chelating the transition metal catalysts.

Reducing power: The reducing capacity of a compound may serve as a significant indicator of its potential antioxidant activity $^{26}$. Fig. 3 shows, the extent of the reduction, in terms of absorbance values at $700 \mathrm{~nm}$. The reducing power of extract (0.093) was concentration-dependent and was found to be below those of ascorbic acid (0.376), BHA (0.457) and tocopherol (0.559) at $125 \mu \mathrm{g} / \mathrm{mL}$. The water extract showed lower reducing power than the standards. Reducing power of extract and standards decreased in order of tocopherol $>$ BHA $>$ ascorbic acid $>$ water extract. The results were in accordance with Farhoosh et $a l^{27}$. They reported that the antioxidant activity of different tea extracts may involve other mechanisms in addition to those of reductones.

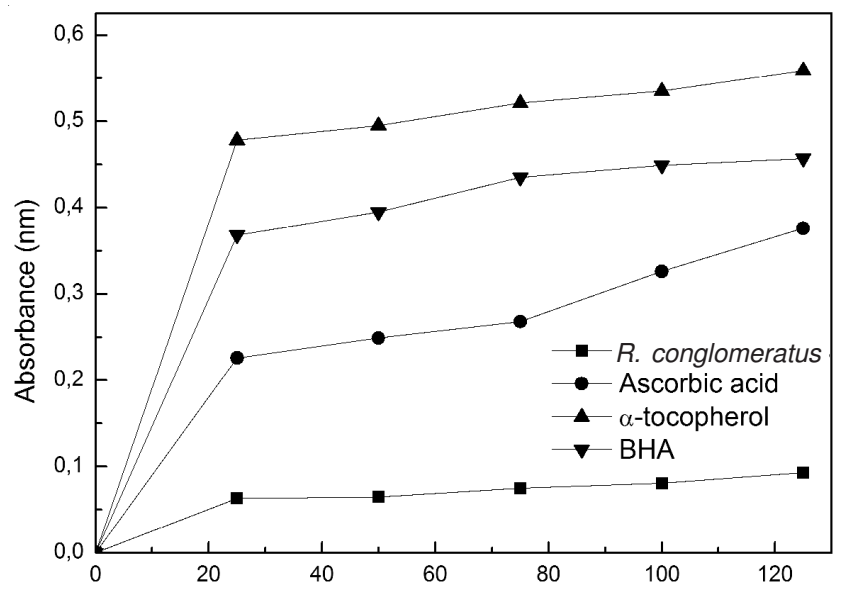

Fig. 3. Reducing power of the extracts from $R$. conglomeratus. $\alpha$ Tocopherol, ascorbic acid and BHA were used as reference antioxidants
DPPH radical scavenging activity: The DPPH radical is considered to be a model for a lipophilic radical. A chain in lipophilic radicals is initiated by the lipid auto-oxidation ${ }^{28}$. DPPH is a stable free radical at room temperature and accepts an electron or hydrogen radical to become a stable diamagnetic molecule ${ }^{29}$. The reduction capability of DPPH was determined by the decrease in its absorbance at $517 \mathrm{~nm}$, which is induced by antioxidants. Positive DPPH test suggests that the samples were free radical scavengers. The scavenging effect of $R$. conglomeratus extract and standards on DPPH radical was compared. The scavenging effect of the $R$. conglomeratus extract on DPPH radicals sharply increased from $25 \mu \mathrm{g} / \mathrm{mL}$ (12\%) to $125 \mu \mathrm{g} / \mathrm{mL}$ (73\%) (Fig. 4). The scavenging effect of the water extract was nearly equal to that of ascorbic acid $(91 \%)$ at a concentration of $50 \mu \mathrm{g} / \mathrm{mL}$. The maximum scavenging effect of tocopherol $(96 \%)$ was reached at a concentration of $50 \mu \mathrm{g} / \mathrm{mL}$. The DPPH radical scavenging activities of water extract and standards were in a increasing order, tocopherol > ascorbic acid $>$ water extract. The result obtained in this investigation revealed that the DPPH radical scavenging activities of water extract might be attributed to the hydrogen donating ability.

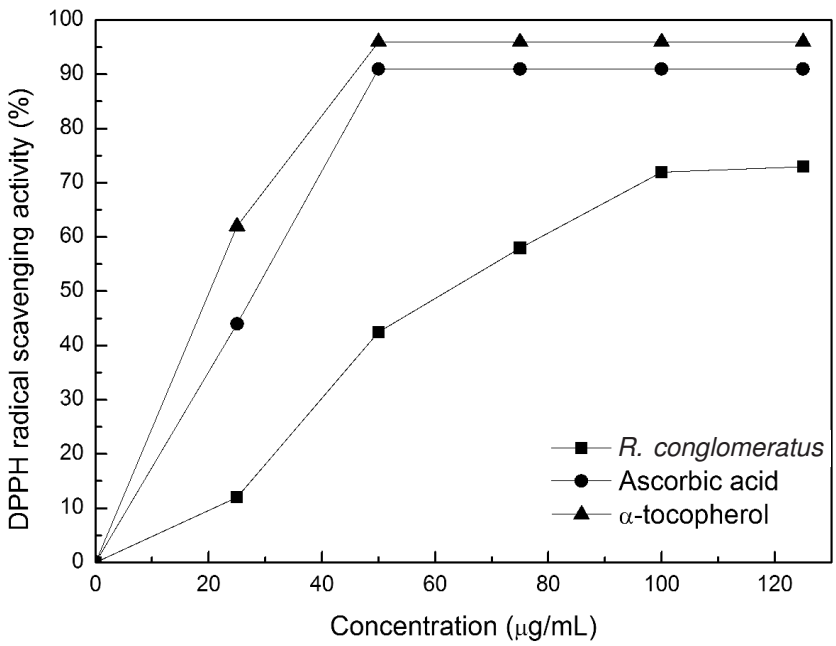

Fig. 4. DPPH radical scavenging activity of the extracts from $R$. conglomeratus. $\alpha$-Tocopherol and ascorbic acid were used as reference antioxidants

ABTS $^{\bullet+}$ scavenging activity: $\mathrm{ABTS}^{\bullet+}$ scavenging activity is also one of the most commonly used methods to evaluate the antioxidant activity. The $\mathrm{ABTS}^{\bullet+}$ scavenging activity of $R$. conglomeratus extract compared to ascorbic acid is shown in Fig. 5. ABTS $^{\bullet+}$ scavenging activity increased with increasing concentration, reaching $11 \%$ at $125 \mu \mathrm{g} / \mathrm{mL}$ and this value was much lesser than that of the positive controls, ascorbic acid $94 \%$ at a same concentration.

\section{Conclusion}

The results of present study reveal that the $R$. conglomeratus contain a considerable amount of phenolic compounds and had significant antioxidant activity. It is believed that the results of this study will contribute to the recent increase in research on using natural products in many areas such as food, pharmacy, alternative medicine and natural therapy. Further studies should be carried out for the evaluation of the in vivo 


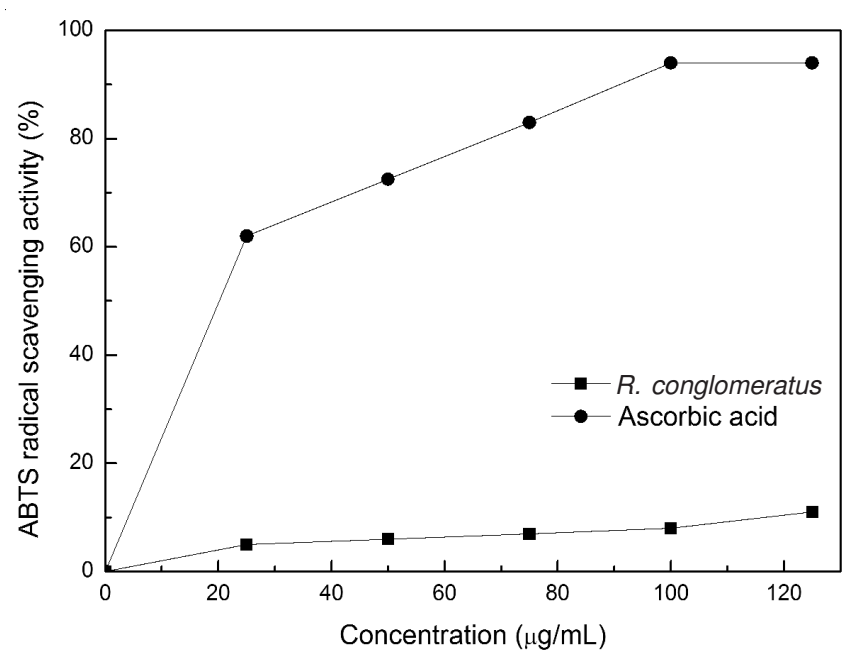

Fig. 5. ABTS radical scavenging activity of the extracts from $R$. conglomeratus. Ascorbic acid was used as reference antioxidant

potential of this extract in animal models and isolation and identification of individual phenolic compounds, as well.

\section{REFERENCES}

1. B. Halliwell, In eds.: O.I. Aruoma and B. Halliwell, The Biological Toxicity of Free Radicals and other Reactive Species, Free Radicals and Food Additives, London: Taylor and Francis, p. 41 (1991).

2. Y. Yesiloglu and L. Sit, Spectrochim. Acta A, 95, 100 (2012).

3. C. Guo, J. Yang, J. Wei, Y. Li, J. Xu and Y. Jiang, Nutr. Res., 23, 1719 (2003).

4. K. Shetty, Process Biochem., 39, 789 (2004).

5. L.Ö. Demirezer, A. Kuruüzüm-Uz, I. Bergere, H.J. Schiewe and A. Zeeck, Phytochemistry, 58, 1213 (2001).

6. R.Q. Mei, H.X. Liang, J.F. Wang, L.H. Zeng, Q. Lu and Y.X. Cheng, Planta Med., 75, 1162 (2009).
7. C. Alasalvar, M. Al-Farsi, P.C. Quantick, F. Shahidi and R. Wiktorowicz, Food Chem., 89, 69 (2005).

8. K. Slinkard and V.L. Singleton, Am. J. Enol. Vitic., 28, 49 (1977).

9. H. Wang, G. Cao and R.L. Prior, J. Agric. Food Chem., 44, 701 (1996).

10. S.L. Bates, R.P. Waldren and I.D. Teare, Plant Soil, 39, 205 (1973).

11. M. Umamaheswari and T.K. Chatterjee, Afr. J. Tradit. Complement. Altern. Med., 5, 61 (2008).

12. K. Dastmalchi, H.L.D. Dorman, P.P. Oinonen, Y. Darwins, I. Laakso, and R. Hiltunen, LWT-Food Sci. Technol., 41, 391 (2008).

13. M. Oyaizu, Nippon Shokulin Kogyo Gakkaishi, 35, 771 (1988).

14. K. Shimada, K. Fujikawa, K. Yahara and T. Nakamura, J. Agric. Food Chem., 40, 945 (1992).

15. R. Re, N. Pellegrini, A. Proteggente, A. Pannala, M. Yang and C. RiceEvans, Free Radic. Biol. Med., 26, 1231 (1999).

16. L.R. Howard, Handbook of Nutraceuticals and Functional Foods, CRC Press, Boca Raton, FL, USA, p. 209 (2001).

17. J.D.J. Ornelas-Paz, E.M. Yahia and A.A. Gardea, Postharvest Biol. Technol., 50, 145 (2008).

18. D. Ruiz, M. Reich, S. Bureau, C.M. Renard and J.M. Audergon, J. Agric. Food Chem., 56, 4916 (2008).

19. I. Konopka, W. Kozirok and D. Rotkiewicz, Food Res. Int., 37, 429 (2004).

20. H.C. Wu, C.Y. Shiau, H.M. Chen and T.K. Chiou, J. Food Drug Anal., 11, 148 (2003)

21. J. Xu, H.X. Yin and X. Li, Plant Cell Rep., 28, 325 (2009).

22. M.A. Hoque, M.N.A. Banu, Y. Nakamura, Y. Shimoishi and Y. Murata, J. Plant Physiol., 165, 813 (2008).

23. S.S. Sharma and K.J. Dietz, J. Exp. Bot., 57, 711 (2006).

24. P. Prieto, M. Pineda and M. Aguilar, Ann. Clin. Biochem., 269, 337 (1999).

25. B. Halliwell and J.M.C. Gutteridge, Biochem. J., 219, 1 (1984).

26. M.R. Bhandari and M. Kawabata, Food Chem., 88, 163 (2004).

27. R. Farhoosh, G.A. Golmovahhed and M.H.H. Khodaparast, Food Chem., 100, 231 (2007).

28. K.U. Ingold, V.W. Bowry, R. Stocker and C. Walling, Proc. Natl. Acad. Sci. USA, 90, 45 (1993).

29. J.R. Soare, T.C. Dinis, A.P. Cunha and L.M. Almeida, Free Radic. Res., 26, 469 (1997). 